\title{
The enneagram model for nursing competencies development- An exploratory qualitative study
}

\author{
Michèle Desmarais*1, Ondina Galiano ${ }^{2}$, Valerie Gazemar ${ }^{2}$, Julie Fréchette ${ }^{1}$ \\ ${ }^{1}$ Ingram School of Nursing, McGill University, Montréal, Canada \\ ${ }^{2}$ Faculty of Nursing, Université de Montréal, Montréal, Canada
}

Received: March 2, 2020

DOI: $10.5430 /$ jnep.v10n8p1
Accepted: April 3, 2020

URL: https://doi.org/10.5430/jnep.v10n8p1
Online Published: April 19, 2020

\begin{abstract}
Background and objective: Nursing competencies can be enhanced by the development of emotional intelligence, which promotes self-knowledge. Personality models, such as the Enneagram model, have been used to develop self-knowledge, and thus may contribute to increasing emotional intelligence. However, few studies have examined perceptions of the use of the Enneagram model on nursing competencies. This qualitative study aims to explore the perceptions of nursing educators and advanced practice nurses about the impact of Enneagram model training on the development of their professional competencies. Methods: This qualitative study used individual interviews and thematic analysis according to Miles and Huberman's method. The nine participants were nursing educators and advanced practice nurses. Interviews were conducted between six and eight weeks after the Enneagram model training.

Results: Results revealed that the Enneagram model may contribute to developing emotional intelligence. Participants perceived the Enneagram model training as promoting better self-awareness and understanding of others. It could also support the development of nursing competencies: humanistic action, collaboration, clinical leadership and support for learning in practice settings.

Conclusions: The use of the Enneagram model could help nurses develop their emotional intelligence and optimize their practice while preserving their mental health. Implications for Nursing Administration: These findings are important for managers responsible for supporting nurses' competencies and mental health through complex care situations in a context of change.
\end{abstract}

Key Words: Nurse competence, Organizational change, Emotional intelligence, Enneagram model, Qualitative research, Mental well-being

\section{INTRODUCTION}

The healthcare system perpetually evolves and inevitably faces challenges due to the increasing complexity of care and reform. ${ }^{[1]}$ These circumstances pose considerable challenges for nursing, therefore highlighting the importance of nursing practices to the quality and safety of care in the health system. ${ }^{[1-3]}$
Managers are responsible for supporting the development of nursing competencies to ensure quality of care. Their responsibilities involve creating, supporting and maintaining quality practice environments that are shared by "nurses, employers, regulatory bodies, professional associations, educational institutions, unions, health service delivery and accreditation organizations, governments and the public". ${ }^{[1]}$ Employers as well as individual nurses, professional organizations, and

\footnotetext{
${ }^{*}$ Correspondence: Michèle Desmarais; Email: michele.desmarais2@mail.mcgill.ca; Address: Ingram School of Nursing, McGill University, Montréal, QC., H3A 2M7, Canada.
} 
other key stakeholders share a common responsibility toward the assurance of competence. ${ }^{[4]}$

Furthermore, the practice of nursing competencies is associated with an improvement in nurses' job satisfaction, nurse retention rate, and organizational sense. ${ }^{[5,6]}$ In addition, it contributes to a decrease in absenteeism from work. ${ }^{[5]}$ In fact, the deployment of nursing competencies contributes to improving the quality and safety of care ${ }^{[1,5,7,8]}$ At the same time, it reduces health care costs and increase the efficiency of care. ${ }^{[1,9]}$

While several models and training programs support the deployment of professional competencies through the development of emotional intelligence, the Enneagram model tends to emerge as a promising avenue. ${ }^{[10]}$ However, the use and impact of this model in the North American context are poorly documented, particularly in nursing. This qualitative study aims to explore the perceptions of nursing educators and advanced practice nurses regarding the quality, relevance, and impacts of the training of this model on the development and exercise of their professional competencies.

\section{BACKGROUND}

Although there has been confusion about the definition of nursing competencies in recent decades, ${ }^{[11]}$ professional organizations agree that competence refers to knowledge, competencies and judgment. ${ }^{[4]}$ The American Nurses Association defines competence as follows:

An expected level of performance that integrates knowledge, skills, abilities, and judgment. The integration of knowledge, skills, abilities, and judgment occur in formal, informal, and reflective learning experiences. [...] Competencies include communication, interpersonal, and problem solving. ${ }^{[4]}$

The American Nurses Association Leadership Competency Framework $^{[4]}$ highlights the importance of leading yourself, others and the organization. The nurse manager must, among other things, build interpersonal relationships with integrity, have self-awareness, communicate effectively, and can resolve conflicts. These elements can be optimized by the development of emotional intelligence. ${ }^{[5,11,12]}$

In nursing, emotional intelligence can promote critical thinking skills, ${ }^{[13]}$ and the practice of nursing competencies, such as leadership, ${ }^{[5,12,14]}$ professionalism, ${ }^{[15]}$ interprofessional collaboration, ${ }^{[16]}$ support for learning and acting with humanism. ${ }^{[12]}$ In addition, it would provide transformational leadership that promotes effective teamwork and quality patient care. ${ }^{[17]}$ Although inconsistencies regarding emotional intel- ligence are reported in nursing practice, the literature raises four common attributes: self-awareness, self-management, social awareness and social/relationship management. ${ }^{[18]}$ The definition of Goleman ${ }^{[19]}$ was used in this research because it comes from the theory of emotional intelligence that has most influenced nursing research. ${ }^{[2,12,20]}$ According to Goleman, ${ }^{[19]}$ emotional intelligence is defined as the ability to recognize and advance the understanding of one's own emotions and that of others, to manage them well towards oneself and others, and to motivate oneself and others towards a common goal.

Nursing competencies are believed to be greatly influenced not only by emotional intelligence, but also by personality traits. ${ }^{[12,21,22]}$ In this sense, to develop emotional intelligence, personality models can be used as an education strategy to acquire self-knowledge, ${ }^{[2,23]}$ because the development of emotional intelligence in nursing is considered as a process that can be learnt with effective education strategies. ${ }^{[14]}$

The Enneagram model proposes a dynamic system of personality understanding that promotes introspection and self-knowledge. ${ }^{[10]}$ The literature on this model indirectly refers to the capacities underlying emotional intelligence mentioned by Goleman: ${ }^{[19]}$ development of selfawareness, ${ }^{[10,24,25]}$ self-management, ${ }^{[26]}$ relationship management and conflict resolution. ${ }^{[10,27]}$

In the Western context, although the relevance of the Enneagram model to competency development has been raised across many disciplines, including management, $[10,24,25,28]$ counselling and psychology, ${ }^{[29]}$ psychiatry and behavioral sciences, ${ }^{[30]}$ education, ${ }^{[10,31]}$ social work, ${ }^{[10]}$ psychotherapy, ${ }^{[10]}$ and medicine, ${ }^{[32,33]}$ few studies have been conducted in nursing. ${ }^{[34,35]}$ Indeed, the majority of these have been carried out particularly with a student population in South Korea. ${ }^{[36-41]}$ These quantitative research studies show that a training program on this model reduces anxiety, ${ }^{[39]}$ while improving self-awareness, ${ }^{[37,41]}$ self-acceptance, ${ }^{[38]}$ communication, ${ }^{[41]}$ interpersonal relationships ${ }^{[37,41]}$ and selfleadership. ${ }^{[37]}$ To our knowledge, no qualitative research has been conducted on a training program based on the Enneagram model in a western context. In response to the demand from healthcare settings in the Quebec (Canada) health network for training to support the competencies of nursing educators and advanced practice nurses, a French-language training program was developed by the researcher and delivered in institutions that have expressed the need. The training was based on a rigorous literature review as suggested by the Medical Research Council. ${ }^{[42]}$ For feasibility, the training of this study had to be limited to one day (seven hours). The pedagogical strategies used were presentation, group 
discussion and dyad exercises. The training was pilot-tested three times in terms of rigorous study, training content and pedagogical strategies. ${ }^{[35]}$

\section{METHOD}

\subsection{Sample}

The sample consisted of nine participants assuming the role of nursing educators or advanced practice nurses working in one Canadian Integrated University Centre for Health and Social Services. They were aged between 34 and 63 (average: 51 years). On average, they had 26 years of practice as nurses (standard deviation $=9.7$ ) and seven years of practice as nursing educators and advanced practice nurses (standard deviation $=3.3$ ) in geriatrics, psychiatry, surgery, and medicine. Two participants had obtained a graduate degree in nursing and seven have a bachelor's degree in nursing. Their main functions were orientation of new employees, clinical coaching, competency assessment, coaching staff with competency difficulties, design, updating and training of caregivers. In addition, no participant had any prior knowledge of the Enneagram model.

\subsection{Data collection}

The development of the Enneagram training followed the recommendation of the Medical Research Council. ${ }^{[42]}$ A review of the literature provided relevant information to develop the Enneagram training. In nursing, the duration of the training varied between 16 and 38 hours: e.g., $24 \mathrm{~h},{ }^{[37]} 16$ hours, ${ }^{[41]}$ and 38 hours. ${ }^{[38]}$ It would have been appropriate to provide training for at least 16 hours. However, for feasibility in the clinical settings, the training duration had to be limited to a one-day training session (7 hours). Once the training was developed, it was pilot-tested three times in order to resolve potential difficulties, in terms of both the content and the teaching strategies. The training included two modules of three and a half hours each (e.g., self-knowledge and leadership, using the Enneagram model), followed by four capsules sent by email approximately nine days apart following the initial seven-hour training.

Between six and eight weeks after the training, participants were interviewed for a semi-structured one-on-one interview using an interview guide, ${ }^{[43]}$ recorded on digital audio tape. The duration of the interviews was between 19 minutes and 102 minutes $($ mean $=62$ minutes, standard deviation $=28$ minutes). A socio-demographic survey was completed at the beginning of the interview. The interviews were conducted from April to May 2017.

Published by Sciedu Press

\subsection{Data analysis}

The data analysis method was performed according to the method developed by Miles and Huberman. ${ }^{[4]}$ The recordings of the interviews were transcribed verbatim, ensuring that everything had been proofread. During the data condensation, ${ }^{[44]}$ the first interview was completely counter-coded by two supervisors to validate the principal researcher's coding. An interjudge agreement rate of about $80 \%$ was achieved. Regular discussions were held between the researcher and the supervisors to validate the codes used. The QDA-Minor software was used to codify and manage data. The thematic analysis was done after the simple coding and the data reduction work. ${ }^{[44]}$ Three themes were identified: "training", "training impact" and "network transformation". The "training" code includes positive and negative aspects, and suggestions for content and format. The "training impact" code implies professional impacts related to professional competencies and personal impacts. Finally, the "network transformation" code was associated with data related to the impacts of the network transformation and the relevance of the Enneagram model in this context. Then, the data presentation steps ${ }^{[44]}$ were performed to order information into tabular matrices, therefore providing a visual representation for analysis. For example, tables were used to qualify whether participants perceived that the model could promote the development of a skill, or that the model promoted the development of that skill. Finally, the researcher remained open to the emergence of unexpected conclusions throughout the process, ${ }^{[44]}$ while reflecting, discussing and verifying codes and themes with the supervisors.

\subsection{Quality assurance}

For the credibility criterion, ${ }^{[44]}$ the use of the verbatim transcription clearly demonstrated that the analysis was derived from the participants. The principal researcher documented in her journal her impressions and preconceptions, to discuss them with her research supervisors in order to avoid bias. The logbook ${ }^{[45]}$ contained the principal researcher's reflections using analytic memos on the researcher's methodology, thoughts, reflections, impressions and preconceptions. To meet the reliability criterion, ${ }^{[46]}$ the logbook enabled the researcher to document the methodology, ${ }^{[47]}$ theoretical notes and personal notes. ${ }^{[45]}$ For the transferability of the results, a comprehensive description of the context, process and content ${ }^{[46]}$ was recorded in the logbook. Finally, for the confirmation criterion, ${ }^{[48]}$ the data collected were classified by data collection method and by chronology.

\subsection{Ethical consideration}

This project was approved by the ethics committees of the health organizations in which the research was conducted 
and by the University of Montreal. The participants completed a consent form. Furthermore, if participants had felt negative emotions during the research process, they could have been referred to the Employee Assistance Program (n $=0$ ). No participants needed to use this support during the study.

\section{RESUlts}

This exploratory study showed that this model could support the development of several nursing skills, including humanism, collaboration, clinical leadership and education in clinical settings.

\subsection{Self-awareness and knowledge of others \\ 4.1.1 Self-awareness}

All participants (9/9) affirmed that the Enneagram is a model that can allow self-awareness. Furthermore, a majority of participants (7/9) noted that the Enneagram model prompted a reflection on their personality. One of them said: "I discovered things about myself [...] It opened my eyes to the fact that we all really have a different personality type and that we have to adjust to different personalities" (P9). Regarding emotional self-awareness, most participants (6/9) expressed that they had a better understanding of their emotions following the training and that it was the "beginning of a process" (P5) of introspection. Some (2/9) mentioned they have better understanding of their anger and wanted to be able to understand it better to maintain harmonious relationships with their colleagues. In addition, through the context of health network transformation, many (4/9) said that the model could help them manage the emotions related to the impacts of transformation, including "frustration", as well as better understanding of themselves and connecting with their motivation, by finding meaning in their work (P1, P4, P9).

\subsubsection{Knowledge of others}

Participants pointed out that learning about personality types reminded them of the importance of a personalized interpersonal approach (9/9) and not a "one size fits all" method (P1, P7, P9). Most participants (7/9) used the Enneagram model with their families to better understand conflict situations, their dynamics and their needs. Also, many (5/9) mentioned better understanding the emotions of their family members: "I was surprised during the class. I started thinking: "My God, that's where I saw my daughter and I've never seen her on that side" (P2).

\subsection{Humanistic nursing competencies}

The results of this research indicate that training on the Enneagram model could support the development of several nursing competencies:

\subsubsection{Leadership}

All participants (9/9) perceived that the model could support their leadership development, particularly to influence positively organizational stakeholders:

It [the Enneagram model] can help in, yes, in this context of health organization transformation [...] it would be nice to be able to identify a little more the type of personality of people and if they are less open to change, to be able to influence them and have them on your team so that it is a win-win situation. (P5)

In this regard, some point to the loss of leadership (3/9), which is an important consequence of the transformation of the health network leading to "frustration" among nursing educators and bedside nurses (P1, P8, P9) who no longer feel they are providing the best quality of care to patients. Two of these three participants pointed out that this model would be particularly relevant for the manager's leadership. Another participant also explained the relevance of the model in the context of change:

In these big reorganizations, sometimes the meaning of our work is a little bit lost. To be able to convince the person of his or her sense of work, you must go and see in his or her personality what is important to him or her. (P2)

\subsubsection{Interprofessional collaboration}

A large majority of participants recognized the relevance of the Enneagram model for interprofessional collaboration (9/9). More specifically, most participants (8/9) mentioned that this could help them to better interact in interprofessional and intraprofessional collaboration, due to significant organizational instabilities and changes. They specified that they must interact with new colleagues by being in new teams and that the Enneagram model allows them to identify their personality more quickly to have relationships. At this point, one third of the participants (3/9) reported using the model with co-workers and had a positive impact on interprofessional collaboration.

In addition, almost half of the participants (4/9) reported that they improved their leadership following the training. For example, one of them claimed to have had an influence on a guidance nurse through the identification of her safety needs. She then said she was better able to exercise her leadership through more open and empathetic communication when supervising this nurse. Other participants (2/9) mentioned it as a potential application to improve interprofessional communication and leadership among nurses working with an 
orderly and nursing assistant : "Yes, yes, it would be relevant [to learn the Enneagram model] [...] to mobilize their team, increase communication with their team and precisely lead their team" (P9). Regarding conflict management, a few participants (3/9) explained that they used the Enneagram model to analyze a conflict situation.

\subsubsection{Support for the learning of the nurse}

All participants (9/9) said that the Enneagram model could help support the learning of novice nurses. Several participants (6/9) reported that, following the training, they further analyzed their approach to supporting learning: "When I have difficulties or when it doesn't 'fit', when I would like to know why it doesn't 'do' so that I can be a caregiver. [...] My role is to supervise and help develop them in my profession" (P4). Two suggested that the Enneagram model be taught to nursing students : "As a teacher, I think it is important to get students to know the Enneagram so that they know their personality type [...], to get to know each other better and to better direct their careers" (P3). Finally, one participant suggested that this model be used by managers, particularly in the context of health system transformation, to ensure a more constructive and humane follow-up of competencies with individuals: "I think it would allow them to better motivate them [nurses] and make this experience more constructive, I think it would be even more relevant for nursing advisors and managers" (P9).

\section{Discussion}

\subsection{Collaboration}

In the health care context of perpetual and inevitable challenges, the findings and results of this research show that the Enneagram model could help nurse educators and advanced practice nurses to better collaborate in teamwork, due to instabilities and significant organizational changes. The results tend to demonstrate the relevance of the Enneagram model to promote intra-professional collaboration. The results are consistent with Ball's findings ${ }^{[34]}$ that the Enneagram model can help resolve conflicts between nurses to ensure a cohesive care team with the goal of providing optimal quality of care. In the same way, a training program based on the Enneagram model can promote the development of communication ${ }^{[41]}$ and interpersonal relationships ${ }^{[37,41]}$ through a better understanding of self and emotions. Being emotionally self-aware promotes an effective emotional regulation by identifying negative emotions, regulating them and not "contaminating" the team with them. Emotional intelligence and the management of one's own emotions would also allow team members to be more open to the views of their colleagues in a problem and conflict resolution process, thus improving team performance. ${ }^{[4]}$ To support interprofessional collaboration, training in the Enneagram model could be relevant to all health professionals such as managers, nurses and nursing students.

\subsection{Implications for novice nurses}

Furthermore, the results indicate that the Enneagram model could help experienced nurses support the learning of novice nurses. At this point, nurses in the role of educating students would greatly need to develop their emotional intelligence to better support learning. ${ }^{[50]}$ This model could help increase effective and empathic communication between novice nurses and managers. At this point, newly graduated nurses reported that they were often verbally abused by experienced senior nurses, physicians, residents and paramedical teams, without managers addressing these issues, resulting in disillusionment, resentment and moral distress among the next generation of nurses. ${ }^{[51]}$ To support novice nurses, an Enneagram model training could be an innovative education strategy to develop harmonious working relationships, ${ }^{[52,53]}$ because the relationship between the novice nurse and the experienced nurse or manager should be more collaborative than hierarchical in nature, particularly in nursing. ${ }^{[51]}$ Enneagram training during the initial formation in nursing (e.g., College and University) and at the beginning of the nursing career could be relevant to develop self-knowledge and confidence. Administrators, managers and educators should implement a preceptor program to increase retention of new graduate nurses. ${ }^{[54,55]}$ The results of the present research indicate the relevance to include an Enneagram model training in a preceptor program to promote harmonious communication between nurses and managers, therefore building a relationship of trust. While managers carry out administrative tasks, such as scheduling and labor replacement, they could benefit from the advantages of the Enneagram model, making them more accessible as a result of greater sensitivity to their own emotions and those of others.

\subsection{Mental health of nurses}

In terms of self-awareness impact, participants recognized that better self-awareness through the Enneagram model could help them to better understand themselves and their motivations, by making sense of their work and better regulating their emotions related to the impacts of the transformation of the health network. Organizational transformation contexts can undermine nurses' mental health. ${ }^{[56,57]}$ In addition, all health professionals may be at risk of burnout and compassion fatigue at some point in their careers. ${ }^{[58,59]}$ Professionals with developed emotional intelligence would be less at risk of burnout, such as physicians ${ }^{[60]}$ and nurses. ${ }^{[61]}$

In this context, all health professionals could benefit from 
training on the Enneagram model to promote the development of emotional intelligence and thus prevent burnout. However, further research would be required to evaluate the effects of the Enneagram model on teamwork, performance, mental health of professionals and quality of care.

\subsection{Limitations}

Our study does not provide information about how newly qualified nurses or advanced beginners experience complex nursing care situations. Although the results of this study are not generalizable beyond the immediate setting due to a small sample size in one Canadian city, these results highlight the potential of the Enneagram model. Another limitation is that the training and the interviews were performed by the principal researcher, thus causing potential biases, such as a social desirability bias in participants. To reduce bias, the principal researcher documented in her journal her impressions and preconceptions, to discuss them with her research supervisors. The journal was used to foster reflexivity and self-awareness from the principal researcher.

\subsection{Implications for nursing administration and recom- mendations}

To provide quality and safety care, managers have a key role in supporting employees through organizational transformation contexts by encouraging the optimal exercise of nurses' competencies. This research provided results on the potential of the Enneagram model to develop leadership, interprofessional collaboration and support for learning through better self-awareness and understanding of others, among nurses, nursing educators, advanced practice nurses, preceptors and employees. The results of this research showed that the Enneagram model could be used in nursing management.

Finally, the results indicate the potential of the Enneagram model to help nurses adapt to change by promoting their mental health through self-awareness in a challenging and complex context of care. While the mental health of professionals and the novice nurses is compromised, it is more relevant to promote the development of emotional intelligence supporting the well-being of professionals, stress management, staff retention, reduced absences due to illness, and beneficial effects for patients. ${ }^{[62,63]}$ In order to prevent burnout, it would be desirable to offer training on the Enneagram model to nurses and managers.

\subsection{Future Research}

The results of this research suggest several implications for future research. The first implication to be drawn is that the development of emotional intelligence using the Enneagram model was perceived as relevant among nurses in the everchanging context of the healthcare system. Second, nurses, regardless of their level of education and credentials, could benefit from Enneagram model training to optimize their competencies and ensure the maintenance of their mental health and well-being. Future research is needed to understand, support and document the impacts of the Enneagram model in healthcare education, thus leading to evidencebased knowledge regarding its use.

\section{Conclusion}

This qualitative study aimed to explore the perceptions of nursing educators and advanced practice nurses about the quality, relevance, and impact of Enneagram training on the development and exercise of their professional skills. The results indicate that Enneagram training may foster better self-awareness and understanding of others, therefore supporting the development of several nursing skills for nurses and managers.

\section{ACKNOWLEDGEMENTS}

The authors would like to thank the nurses who tested the Enneagram training and gave their comments. They also want to acknowledge the engagement of the nurses who participated in the interviews, the supervisory committee and colleagues. The principal author would like to thank the Ministère de l'Éducation et de l'Enseignement supérieur and the Association québécoise des infirmières et infirmiers en santé mentale for their Master's funding.

\section{CONFlicts of Interest Disclosure}

The Authors declare that there was no conflict of interest during the research. The first author offered training sessions on the Enneagram model for Quebec associations and hospitals from 2017 to 2019.

\section{REFERENCES}

[1] Association des infirmières et infirmiers du Canada. Cadre de pratique des infirmières et infirmiers au Canada [Internet] 2nd ed. Ottawa: Association des infirmières et infirmiers du Canada; 2015 Nov. [cited 2019 Dec. 9]. Available from: https://www.cna-aiic.ca/ /media/cna/page-content/p $\mathrm{df}-\mathrm{fr} / \mathrm{cadre}$-de-pratique-des-infirmieres-et-infirmi ers-au-canada.pdf?la=fr

[2] Roussel L. Management and leadership for nurse administrators. 6th ed. Burlington (MA): Jones \& Bartlett Learning; 2013.

[3] Grossman S. The new leadership challenge : creating the future of 
nursing. 3rd ed. Valiga TM, editor. Philadelphia: F.A. Davis; 2009.

[4] America Nurses Association. ANA Leadership: Competency Model [Internet]. United States of America: American Nurses Association; 2018 Jul. [cited 2019 Dec 3]. Available from: https: //www.nursingworld.org/ 4a0a2e/globalassets/docs/ce /177626-ana-leadership-booklet-new-final.pdf

[5] Cummings GG, MacGregor T, Davey M, et al. Leadership styles and outcome patterns for the nursing workforce and work environment: A systematic review. Int J Nurs Stud. 2010; 47(3): 363-85. PMid:19781702 https://doi.org/10.1016/j.ijnurstu. 200 9.08 .006

[6] Registered Nurses' Association of Ontario. Developing and Sustaining Nursing Leadership [Internet]. 2nd ed. Toronto (ON): Registered Nurses' Association of Ontario; 2013 Jul. [cited 2019 Dec. 19]. Available from: https://rnao.ca/sites/rnao-ca/files/Leader shipBPG_Booklet_Web_1.pdf

[7] Durand S, Laflamme F, editors. Pratique infirmière avancéeRéflexion sur le rôle de l'infirmière clinicienne spécialisée [Internet]. Montreal: Ordre des infirmières et infirmiers du Québec; 2016. [cited 2019 Dec. 12]. Available from: http://www . anfiide-gic-repasi.com/wp-content/uploa ds/2014/07/8456-reflexion-role-ics.pdf

[8] National Association of Clinical Nurse Specialists. Impact of the Clinical Nurse Specialist Role on the Costs and Quality of Health Care [Internet]. Reston: National Association of Clinical Nurse Specialists; 2013 Dec. [cited 2020 Jan. 7]. Available from: https://nacns.org/advocacy-policy/position-stateme nts/impact-of-the-clinical-nurse-specialist-role-o n-the-costs-and-quality-of-health-care/

[9] Vosit-Steller J, Morse AB. Consultation. In: Hamric AB, Hanson CM, Tracy MF, O'Grady ET, editors. Advanced practice nursing: an integrative approach. 5e ed. Missouri: Elsevier; 2014. p. 213-36.

[10] Bland AM. The Enneagram: A Review of the Empirical and Transformational Literature. Journal of Humanistic Counseling, Education and Development. 2010; 49(1): 16-31. https://doi.org/10.100 2/j.2161-1939.2010.tb00084.x

[11] Fukada M. Nursing Competency: Definition, Structure and Development. Yonago Acta Med. 2018; 61(1): 1-7. https ://doi .org/10 .33160/yam. 2018.03.001

[12] Bulmer Smith K, Profetto-McGrath J, Cummings GG. Emotional intelligence and nursing: An integrative literature review. Int J Nurs Stud. 2009; 46(12): 1624-36. PMid:19596323 https://doi.org/ $10.1016 / j$. ijnurstu. 2009.05.024

[13] Christianson KL. Emotional Intelligence and Critical Thinking in Nursing Students: Integrative Review of Literature. Nurse Educ. 2020. PMid:32091477 https://doi.org/10.1097/NNE. 000000 0000000801

[14] Carragher J, Gormley K. Leadership and emotional intelligence in nursing and midwifery education and practice: a discussion paper. J Adv Nurs. 2017; 73(1): 85-96. PMid:27607451 https: //doi.org/10.1111/jan.13141

[15] Grossman S, Valiga TM. The new leadership challenge : creating the future of nursing. 4th ed. Philadelphia: F.A. Davis; 2013.

[16] Quoidbach J, Hansenne M. The Impact of Trait Emotional Intelligence on Nursing Team Performance and Cohesiveness. J Prof Nurs. 2009; 25(1): 23-9. PMid:19161959 https://doi.org/10.1016/ j . profnurs . 2007.12.002

[17] Fischer SA. Transformational leadership in nursing: a concept analysis. J Adv Nurs. 2016; 72(11): 2644-53. PMid:27322510 https://doi.org/10.1111/jan.13049

[18] Raghubir AE. Emotional intelligence in professional nursing practice: A concept review using Rodgers's evolutionary analysis ap- proach. International Journal of Nursing Sciences. 2018; 5(2): 126-30. PMid:31497624 https://doi.org/10.1016/j.ijnss. 2018.0 3.004

[19] Goleman D. L'intelligence émotionnelle au travail. Boyatzis RE, McKee A, editors. Paris: Village Mondial; 2002.

[20] Akerjordet K, Severinsson E. The state of the science of emotional intelligence related to nursing leadership: an integrative review. J Nurs Manag. 2010; 18(4): 363-82. PMid:20609041 https : //doi.org/10.1111/j.1365-2834.2010.01087.x

[21] Beauvais AM, Brady N, O'Shea ER, et al. Emotional intelligence and nursing performance among nursing students. Nurse Educ Today. 2011; 31(4): 396-401. PMid:20739106 https://doi .org/10.1 016/j.nedt. 2010.07.013

[22] Heydari A, Kareshki H, Armat MR. Is Nurses' Professional Competence Related to Their Personality and Emotional Intelligence? A Cross-Sectional Study. J Caring Sci. 2016 Jun 1; 5(2): 121-32. PMid:27354976 https://doi.org/10.15171/jcs.2016.013

[23] Phaneuf JE. Émergence des comportements de leadership transformationnel: examen de l'apport d'une approche basée sur les composites de personnalité et d'une perspective interactionniste [Dissertation] [Montréal]: Université de Montréal; 2015. 180p.

[24] Delvo MK. The Enneagram as a Facilitator of Self-Awareness in Emerging Leader Programs. [Master's thesis]. [Minnesota]: University of Minnesota; 2015. $66 \mathrm{p}$.

[25] Chestnut B. The 9 Types of Leadership: Mastering the Art of People in the 21st Century Workplace. New York: Post Hill Press; 2017.

[26] Lapid-Bogda G. Bringing out the best in everyone you coach: use the enneagram system for exceptional results. New York: McGraw-Hill; 2010.

[27] Taylor C. The process enneagram: A practitioner's guide to its use as a facilitative tool in the corporate environment. Emergence: Complexity and Organization. 2013; 15(1): 55-70.

[28] Mladkova L. The enneagram as a tool of management of knowledge workers. Proceedings of the European Conference on Knowledge Management, ECKM. 2016; 2016-January: 614-21.

[29] Matise M. The Enneagram: An Enhancement to Family Therapy. Contemporary Family Therapy : An International Journal. 2019; 41(1): 68-78. https://doi.org/10.1007/s10591-018 $-9471-0$

[30] Daniels D, Saracino T, Fraley M, et al. Advancing Ego Development in Adulthood Through Study of the Enneagram System of Personality. Journal of Adult Development. 2018; 25(4): 229-41. PMid:30416328 https://doi.org/10.1007/s10804-018-9289-x

[31] Roh H, Park KH, Ko HJ, et al. Understanding medical students' empathy based on Enneagram personality types. Korean J Med Educ. 2019 Mar; 31(1): 73-82. PMid:30852863 https ://doi.org/10.3 946/kjme.2019.120

[32] Komasi S, Zakiei A, Ghasemi S, et al. Is enneagram personality system able to predict perceived risk of heart disease and readiness to lifestyle modification? Ann Card Anaesth. 2019; 22(4): 394-9. PMid:31621675 https : //doi .org/10.4103/aca.ACA_115_18

[33] Saeid K, Ali S, Nasrin N, et al. Enneagram Personality System as an Effective Model in Prediction of Risk of Cardiovascular Diseases: A Case-Control Study. Journal of Cardio-Thoracic Medicine. 2016; 4(3): 468-73.

[34] Ball E. Do professions have distinct or singular personalities? Using the enneagram to support and facilitate inter-professional nursing. Nurse Educ Today. 2009; 29(3): 365-6. https ://doi .org/10.1 016/j.nedt. 2009.02.001

[35] Desmarais M. Perceptions des conseillères en soins infirmiers et en pratique infirmière avancée quant à la qualité, à la pertinence et aux 
impacts d'une formation à l'Ennéagramme sur les compétences infirmières [Master's thesis]. [Montréal]: Université de Montréal; 2017. $97 \mathrm{p}$.

[36] Kim S. A Study on Employment Uneasiness, Appearance Satisfaction and Self Expression by Enneagram Type of Nursing Students. Korean Association for Learner-Centered Curriculum And Instruction. 2019; 19. https://doi.org/10.22251/jlcci.2019.19.14.691

[37] Kim WG, Cho Chung HI. Effects of Korean Enneagram Program on the Ego-identity, Interpersonal Relationship, and Self-leadership of Nursing College Students. Journal of Korean Academy of Nursing Administration 2015; 21(4): 393-404. https ://doi .org/10.111 11/jkana.2015.21.4.393

[38] Lee JS, Yoon JA, Do KJ. Effectiveness of enneagram group counseling for self-identification and depression in nursing college students. Journal of Korean Academy of Nursing. 2013; 43(5): 649. PMid:24351996 https : //doi.org/10.4040/jkan.2013.43.5 .649

[39] Koo HY. Effects of the Enneagram Group Counseling Program on Self-esteem, Anxiety and Interpersonal Relationships in Nursing Students. Journal of Nurses Academic Society of Nursing Education. 2011; 17: 446-55.

[40] Lee MR. Effects of the Enneagram Group Counseling Program on ego-resilience and empathy ability in nursing students. Journal of Gaya University. 2011; 19: 281-93.

[41] Lee MR. A Study on the Effects of Enneagram Group Counseling on Nursing Students. International Journal of Bio-Science and BioTechnology. 2015; 7: 235-46. https ://doi.org/10.14257/ijb sbt.2015.7.5.22

[42] Craig P, Dieppe P, Macintyre S, et al. Developing and evaluating complex interventions: the new Medical Research Council guidance. BMJ. 2008; 337: a1655. PMid:18824488 https://doi.org/10.1 $136 / \mathrm{bmj}$. a1655

[43] Savoie-Zajc L. L'entrevue semi-dirigée. In: Gauthier B, editor. Recherche sociale: de la problématique à la collecte des données. 5e ed. Québec: Presses de l'Université du Québec; 2009. p. 337-364.

[44] Miles MB, Huberman AM. Analyse des données qualitatives. 2nd ed. Huberman AM, editor. Paris: De Boeck Université; 2003.

[45] Mucchielli A. Dictionnaire des méthodes qualitatives en sciences humaines et sociales 3rd ed. Paris : Armand Colin; 2009.

[46] Stringer ET. Action research. 3rd ed. Los Angeles: Sage Publications; 2007.

[47] Koch T, Kralik D. Participatory Action Research in Health Care. Australia: Wiley-Blackwell; 2006.

[48] Guba EG, Lincoln YS. Fourth generation evaluation. Newbury Park: Sage Publications; 1989.

[49] Jordan PJ, Troth AC. Managing Emotions During Team Problem Solving: Emotional Intelligence and Conflict Resolution. Human Performance. 2004; 17(2): 195-218. https ://doi.org/10.1207/ s15327043hup1702_4

[50] Freshwater D, Stickley T. The heart of the art: emotional intelligence in nurse education. Nurs Inq. 2004; 11(2): 91-8. PMid:15154888 https ://doi.org/10.1111/j.1440-1800.2004.00198.x

[51] Dong D, Temple B. Oppression: a concept analysis and implications for nurses and nursing. Nurs Forum. 2011; 46(3): 169-76.
PMid:21806627 https : //doi.org/10.1111/j.1744-6198.20 $11.00228 . \mathrm{x}$

[52] Lapid-Bogda G. Bringing Out the Best in Yourself at Work. Blacklick (USA): McGraw-Hill Professional Publishing; 2004.

[53] Lapid-Bogda G. What type of leader are you? : using the Enneagram system to identify and grow your leadership strengths and achieve maximum success. New York: McGraw-Hill; 2007.

[54] Halter M, Pelone F, Boiko O, et al. Interventions to Reduce Adult Nursing Turnover: A Systematic Review of Systematic Reviews. The Open Nursing Journal. 2017; 11(1): 108-23. PMid:29299084 https://doi .org/10.2174/1874434601711010108

[55] Salt J, Cummings GG, Profetto-McGrath J. Increasing retention of new graduate nurses: a systematic review of interventions by healthcare organizations. The Journal of Nursing Administration. 2008; 38(6): 287-96. PMid:18562833 https://doi.org/10.1097/01 .NNA. $0000312788.88093 .2 \mathrm{e}$

[56] Montes-Berges B, Augusto-Landa JM. Emotional intelligence and affective intensity as life satisfaction and psychological well-being predictors on nursing professionals. Journal of professional nursing : official journal of the American Association of Colleges of Nursing. 2014; 30(1): 80-8. PMid:24503319 https ://doi.org/10.1016/ j.profnurs. 2012.12.012

[57] Teo ST, Pick D, Newton CJ, et al. Organisational change stressors and nursing job satisfaction: the mediating effect of coping strategies. J Nurs Manag. 2013; 21(6): 878-87. PMid:23890099 https://doi.org/10.1111/jonm. 12120

[58] van Mol MMC, Kompanje EJO, Benoit DD, et al. The Prevalence of Compassion Fatigue and Burnout among Healthcare Professionals in Intensive Care Units: A Systematic Review. PLOS ONE. 2015; 10(8): e0136955. PMid:26322644 https://doi.org/10.1371/ journal.pone.0136955

[59] Ray SL, Wong C, White D, et al. Compassion Satisfaction, Compassion Fatigue, Work Life Conditions, and Burnout Among Frontline Mental Health Care Professionals. Traumatology (Tallahass Fla). 2013; 19(4): 255-67. https://doi.org/10.1177/1534765612 471144

[60] Weng HC, Hung CM, Liu YT, et al. Associations between emotional intelligence and doctor burnout, job satisfaction and patient satisfaction. Med Educ. 2011; 45(8): 835-42. PMid:21752080 https://doi.org/10.1111/j.1365-2923.2011.03985.x

[61] Lewis GM, Neville C, Ashkanasy NM. Emotional intelligence and affective events in nurse education: A narrative review. Nurse Educ Today. 2017; 53: 34-40. PMid:28426999 https ://doi .org/10.1 $016 / j$.nedt .2017 .04 .001

[62] Codier E, Kamikawa C, Kooker BM. The impact of emotional intelligence development on nurse managers. Nurs Adm Q. 2011; 35(3): 270-6. PMid:21654488 https ://doi .org/10.1097/NAQ. Ob013e3182243ae3

[63] Nightingale S, Spiby H, Sheen K, et al. The impact of emotional intelligence in health care professionals on caring behaviour towards patients in clinical and long-term care settings: Findings from an integrative review. Int J Nurs Stud. 2018; 80: 106-17. PMid:29407344 https://doi.org/10.1016/j.ijnurstu.2018.01.006 